\title{
Thermoelectric Properties of (100) Oriented Silicon and Nickel Silicide Nanocomposite Films Grown on Si on Insulator and Si on Quartz Glass Substrates
}

\author{
Noriyuki Uchida ${ }^{1,}$, Yuji Ohishi ${ }^{2}$, Yoshinobu Miyazaki $^{2}$, Ken Kurosaki $^{2}$, Shinsuke Yamanaka ${ }^{2}$ \\ and Tetsuya Tada ${ }^{1}$
}

${ }^{1}$ Nanoelectronics Research Institute, National Institute of Advanced Industrial Science and Technology, Tsukuba 305-8568, Japan

${ }^{2}$ Graduate School of Engineering, Osaka University, Suita 565-0871, Japan

We have grown (100) oriented composite films of Si and Ni silicide nanocrystals (Ni-Si NC film) on substrates of Si on insulator (SOI) and $\mathrm{Si}$ on quartz glass (SOQ). Owing to improvement of carrier transport properties and reduction of the thermal conductivity in the oriented films, they have higher dimensionless figures of merit, ZT of $0.22-0.42$ for p-type Ni-Si NC film and $0.08-0.13$ for n-type Ni-Si NC film-than that of bulk $\mathrm{Si}(Z T<0.01)$ at $30^{\circ} \mathrm{C}$. The $Z T$ values of p-type and n-type Ni-Si NC films were increased to 0.65 and 0.40 at $500^{\circ} \mathrm{C}$, respectively. [doi:10.2320/matertrans.E-M2016807]

(Received October 23, 2015; Accepted January 23, 2016; Published May 13, 2016)

Keywords: silicon based thermoelectric materials, nanocomposite films, silicon nanostructures, nickel silicide nanocrystals, phonon scattering

\section{Introduction}

Thermoelectric conversion is one of the key technologies for energy harvesting. In order to utilize thermoelectric technology in the wide-ranging situations near the human body, it is necessary to fabricate thermoelectric devices that work at near room temperature (RT), using environmentally safe materials. Silicon is one of the nontoxic and earth-abundant materials. However, it is difficult to use Si for thermoelectric devices since its dimensionless figure of merit, $Z T$, is very small $\left(Z T<0.01\right.$ at $\left.30^{\circ} \mathrm{C}\right)$. The $Z T$ values are given by $Z T=$ $S^{2} T / \rho \kappa$, where $\rho, S, \kappa$, and $T$ are the carrier resistivity, Seebeck coefficient, thermal conductivity, and temperature, respectively. The value of $Z T$ for $\mathrm{Si}$ is low because of its high $\kappa$ value $\left(>100 \mathrm{Wm}^{-1} \mathrm{~K}^{-1} \text { at } \mathrm{RT}\right)^{1)}$. Thus, it is necessary to reduce the thermal conductivity of Si.

It has been pointed out that $\kappa$ can be reduced by forming nanostructures of $\mathrm{Si}$ such as nanowires ${ }^{2,3)}$ and nanocrystals $(\mathrm{NCs})^{4-8)}$ with enhanced phonon scattering at their surfaces and interfaces. Recently, we demonstrated that semiconducting composite films of $\mathrm{Si}$ and $\mathrm{Ni}$ silicide NCs (Ni-Si NC films) on $\mathrm{SiO}_{2}$ (quartz glass) substrates have much lower values of $\kappa\left(3-7 \mathrm{Wm}^{-1} \mathrm{~K}^{-1}\right)$ than bulk Si at $\mathrm{RT}^{6)}$. Much higher ZT values of 0.13 and 0.06 were obtained for heavily-doped p-type and n-type Ni-Si NC films $\left(\sim 10^{20} \mathrm{~cm}^{-3}\right)$, respectively at RT. The absolute values of $S$ for the heavily doped p- and n-type Ni-Si NC films were estimated to be $100-200 \mu \mathrm{V} \mathrm{K}^{-1}$, which compare favorably with those of the Si nanocomposite bulks and single-crystalline Si. However, the electron and hole mobilities of the Ni-Si NC films were reduced by 34 and $55 \%$, respectively, from the values for single-crystalline $\mathrm{Si}$ (c-Si). Thus, to further increase ZT of the Ni-Si NC films, we must improve the carrier-transport properties of the films as well as reduce the thermal conductivity. In the study reported here, we further improved the thermoelectric properties of the $\mathrm{Ni}-\mathrm{Si} \mathrm{NC}$ films by increasing the carrier conductivity through orientational growth of the films on substrates of silicon on

*Corresponding author, E-mail: nori-uchida@aist.go.jp insulator (SOI) and silicon on quartz glass (SOQ).

\section{Experimental}

The thicknesses of the SOI and SOQ layers were 10 and $75 \mathrm{~nm}$ on the box $\mathrm{SiO}_{2}$ layer and the $\mathrm{SiO}_{2}$ substrate, respectively, with crystal orientation of (100). The Ni-Si NC films were synthesized on the SOI and SOQ substrates with phase separation from the amorphous $\mathrm{Ni}-\mathrm{Si}$ alloy films with composition of $\mathrm{NiSi}_{20}$, incorporating $2 \mathrm{~mol} \% \mathrm{~B}$ for p-type $\mathrm{Ni}-\mathrm{Si}$ $\mathrm{NC}$ films and $2 \mathrm{~mol} \% \mathrm{P}$ for n-type $\mathrm{Ni}-\mathrm{Si} \mathrm{NC}$ films, followed by thermal annealing at $800^{\circ} \mathrm{C}$ for $5 \mathrm{~min}$ in a $\mathrm{N}_{2}$ ambient. The amorphous $\mathrm{NiSi}_{20}$ films were deposited by $\mathrm{DC}$ magnetron sputtering of the Ni-Si target with a composition of $\mathrm{Si} / \mathrm{Ni}=$ 20:1 (99.9\%) in a pure Ar atmosphere at a sputtering pressure of $3.3 \times 10^{-3}$ Torr. The $2 \mathrm{~mol} \% \mathrm{~B}$ and $\mathrm{P}$ dopant atoms were includes to the Ni-Si targets. The thickness was controlled in the range $750 \mathrm{~nm}$ to $1 \mu \mathrm{m}$ by deposition time, and measured by profilometer (Dektak 3). For the dopant activation, rapid thermal annealing (RTA) was performed at 1200 or $1230^{\circ} \mathrm{C}$ with infrared-lamp heating for 10 or $20 \mathrm{~s}$ in a $\mathrm{N}_{2}$ ambient. Hereafter, the Ni-Si NC films on the SOI, SOQ, and $\mathrm{SiO}_{2}$ substrates are referred to as (Ni-Si NC film)/SOI, (Ni-Si NC film)/SOQ, and (Ni-Si NC film)/SiO 2 , respectively. We observed the structures of the Ni-Si NC films using cross-sectional transmission electron microscopy (TEM) with electron-beam energy of $300 \mathrm{keV}$. The $\mathrm{Ni}-\mathrm{Si} \mathrm{NC}$ films were characterized by x-ray diffraction (XRD) using Rigaku's Ultima IV system ( $\mathrm{Cu} K_{\alpha} \mathrm{x}$-ray source). To investigate the phonon modes in the Ni-Si NC films, Raman spectra of the films were measured using a continuous-wave $(\mathrm{CW})$ laser with a wavelength of $488 \mathrm{~nm}$ and a power of $0.15 \mathrm{~mW}$, where the excitation laser was focused on the sample through an objective lens with $\times 50$ magnification and a diameter of $2 \mu \mathrm{m}$. The electrical-transport properties of the B- and P-doped $\mathrm{Ni}-\mathrm{Si}$ NC films were characterized with Hall measurements at RT. The in-plane distributions of $S$ and $\kappa$ values of the (Ni-Si NC film)/SOQ were measured using a scanning thermal probe micro-imaging (STPM) system (ULVAC-RIKO Corp.) at 
$\mathrm{RT}^{6,9,10)}$. The $\kappa$ values measured by STPM method reflect the isotropic heat transport from the thermal probe to the $\mathrm{Ni}-\mathrm{Si}$ $\mathrm{NC}$ films. The $\kappa$ values of (Ni-Si NC film)/SOI were also measured by TCN-2 $\omega$ methods (ULVAC-RIKO Corp.) ${ }^{11)}$. Vertical heat transport of film samples are measured by the TCN- $2 \omega$ method, however the method was used to measure thermal conductivities of nanocomposite films in literatures $6,7,12,13)$, because the films had isotropic thermal transport properties owing to the uniformly-distributed phonon scattering center in the films. In the TCN- $2 \omega$ method, the measurement specimen consists of four layers, an $\mathrm{Au}$ thin film, the Ni-Si NC film, and the box $\mathrm{SiO}_{2}$ layer and $\mathrm{Si}$ substrate. The Au film of $100 \mathrm{~nm}$ in thickness was deposited on the Ni-Si NC film by DC magnetron sputtering of an Au target. The Au film was used as a heat source by AC Joule heating and as a temperature sensor for monitoring the heat penetration from $\mathrm{Au}$ film to (Ni-Si NC film)/SOI by a thermo-reflectance technique. The equation of the thermal conduction for the three-layered system has been solved analytically to obtain the $\kappa$ value of Ni-Si NC films ${ }^{11)}$. The temperature-dependent $Z T$ was measured by an electrical-resistance measuring system, (ZEM-3, ULVAC-RIKO Corp.) from 30 to $500^{\circ} \mathrm{C}$.

\section{Results and Discussion}

Figure 1(a) shows the XRD patterns of (Ni-Si NC film)/ $\mathrm{SiO}_{2}$ and (Ni-Si NC film)/SOQ, with sharp peaks that can be indexed to $\mathrm{Si}$ and $\mathrm{NiSi}_{2}$. The $\mathrm{Si}$ and $\mathrm{NiSi}_{2}$ peaks with Miller indices of 111, 220, 311, 331, and 400 are located at the same diffraction angles because the lattice constants of $\mathrm{Si}$ and $\mathrm{NiSi}_{2}$ are almost the same. The 200 peak, which was observed in the XRD patterns of only ( $\mathrm{Ni}-\mathrm{Si} \mathrm{NC}$ film)/SOQ, is assigned to $\mathrm{NiSi}_{2}$ since the crystal symmetry of $\mathrm{Si}$ makes the 200 peak unobservable. In the pattern of (Ni-Si NC film)/SOQ, the 400 peak is prominent and other peaks are negligibly small, indicating that the 100-oriented domains were dominant in the film grown on the SOQ (100) layer. The $\Omega$ scan of 400 peak have small FWHM of $0.15^{\circ}$ indicatingorientation to 100 direction. On the other hand, various crystal orientations of $111,220,311$, and 331 were observed in (Ni-Si NC film)/ $\mathrm{SiO}_{2}$. Under the TEM, orientational growth of domains on the scale of several micrometers was observed in the Ni-Si NC film on the SOI sample, while random domain orientations were observed in (Ni-Si NC film)/ $\mathrm{SiO}_{2}$. Similar orientational growth of domains was observed in both (Ni-Si NC film)/ SOQ and (Ni-Si NC film)/SOI samples. Figures 1(b)-(d) show cross-sectional TEM images of the B-doped Ni-Si NC film after RTA at $1200^{\circ} \mathrm{C}$. We observed bright and dark domains from 100 to $500 \mathrm{~nm}$ in diameter and undulation of the SOI substrate in Fig. 1(b). As was the case for (Ni-Si NC film) $/ \mathrm{SiO}_{2}{ }^{6}$, the bright and dark domains are assigned to the $\mathrm{Si} \mathrm{NCs}$ and $\mathrm{NiSi}_{2} \mathrm{NCs}$, respectively. The formation of $\mathrm{Si} \mathrm{NCs}$ was confirmed by the Raman measurements of (Ni-Si NC film)/SOI, which will be discussed later. NiSi2 NCs of 10$50 \mathrm{~nm}$ in diameter were observed in the Si domains. Moreover, as shown in Fig. 1(c), smaller Ni silicide NCs, which measured 5-10 $\mathrm{nm}$ in diameter, were formed near the interface between the $\mathrm{NiSi}_{20}$ alloy film and the $\mathrm{Si}$ layer of SOI substrate. A secondary ion mass spectrometry measurement

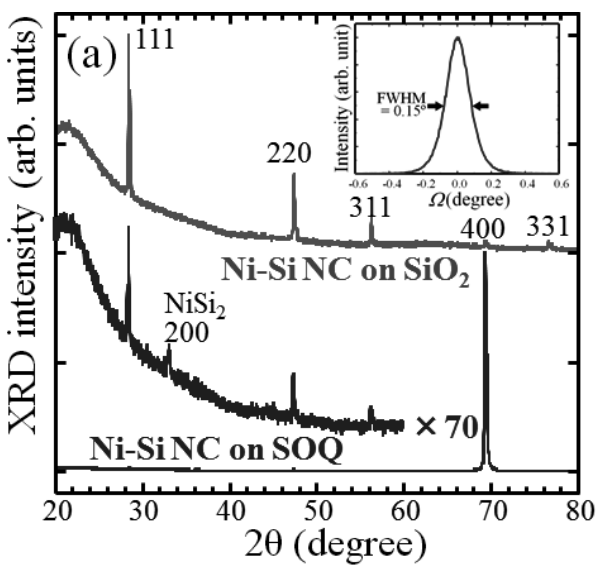

(b)

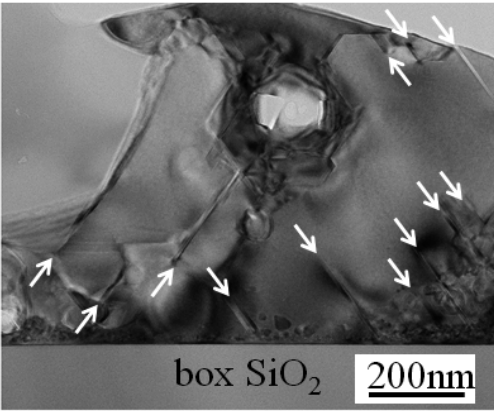

(c)

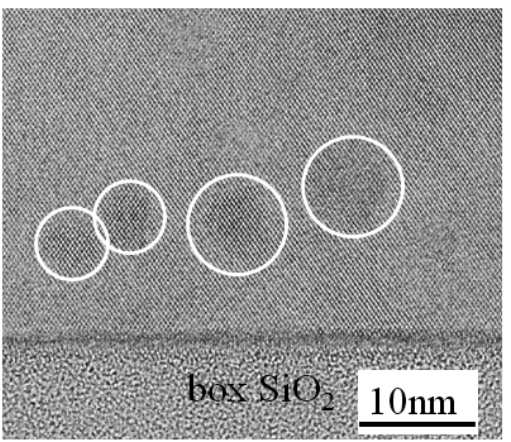

(d)

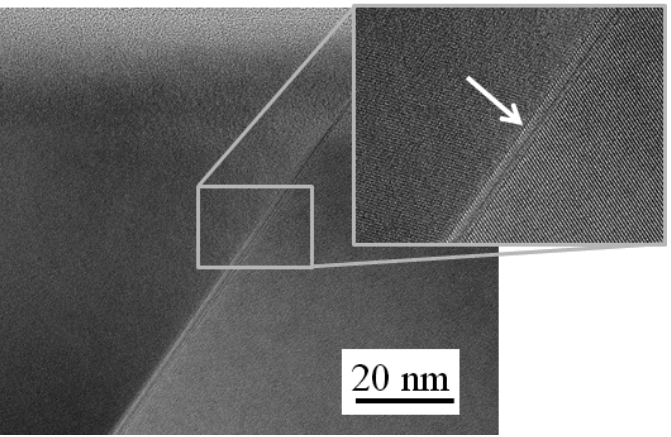

Fig. 1 (a) XRD patterns ( $2 \theta$ scans) of $\mathrm{Ni}-\mathrm{Si} \mathrm{NC}$ films on $\mathrm{SiO}_{2}$ and $\mathrm{SOQ}$ substrates after RTA at $1200^{\circ} \mathrm{C}$, and the and $\Omega$ scan of 400 peak of the $\mathrm{Ni}-\mathrm{Si}$ NC film on SOQ substrates. (b-d) Cross-sectional TEM images of B-doped Ni-Si NC film on SOI substrate after RTA at $1200^{\circ} \mathrm{C}$. The arrows in (b) indicate the positions of planar defects. The circles in (c) highlight the Ni silicide NCs formed in Si domains. The arrow in inset of (d) indicates the position of the twin defect.

indicated diffusion of $\mathrm{Ni}$ and dopant atoms into the SOI and SOQ layers after RTA. Thus, the upper part of the SOI and SOQ layers converted to $\mathrm{Ni}-\mathrm{Si} \mathrm{NC}$ films after annealing. We observed twin and planar defects with higher density in both (Ni-Si NC film)/SOI and (Ni-Si NC film)/SOQ than those in (Ni-Si NC film) $/ \mathrm{SiO}_{2}$ substrate. The arrows in Fig. 1 (b) indicate the position of the planar defects. Owing to the restric- 


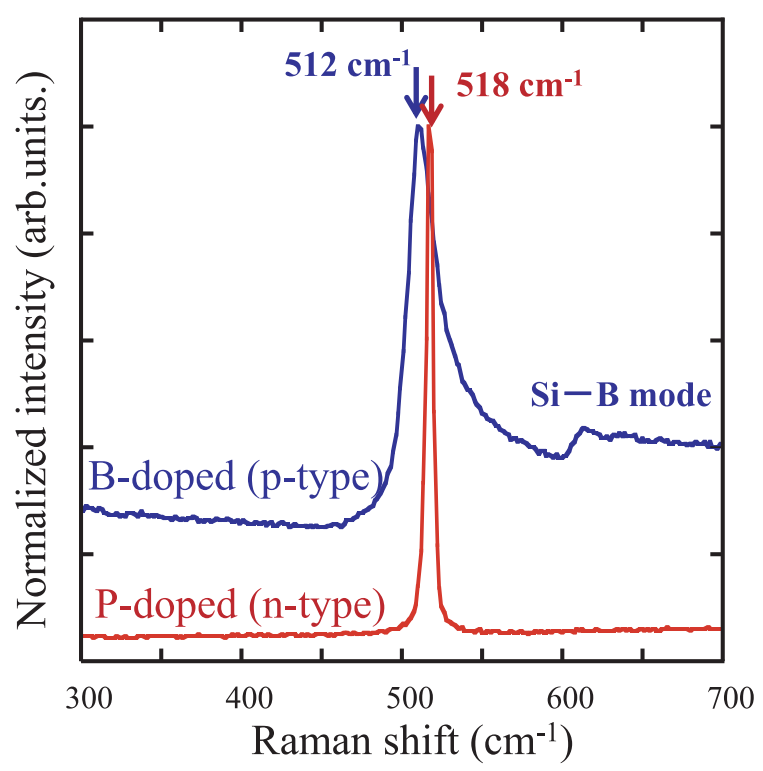

Fig. 2 (a) Raman spectra of p-type and n-type Ni-Si NC films on SOQ substrates after RTA at $1200^{\circ} \mathrm{C}$.

tion on crystal orientation of Si regions in the (100) direction because of the orientational growth, the twin defects were generated at domain boundaries of Si regions in the films on the SOI and SOQ substrates. A typical twin defect located at the domain boundary is shown in Fig. 1(d). These planar and twin defects could serve as scattering centers of phonon ${ }^{6,14)}$, thereby reducing the thermal conductivity of the film. The multiscale hierarchical architecture, such as the domain boundaries, nanostructures and defects, in Ni-Si NC films effectively scatter phonons with wide range of mean free path, resulting in large reduction of the thermal conductivity, as shown in leterature ${ }^{15)}$.

Figure 2 shows Raman scattering spectra of the P- and B-doped (Ni-Si NC film)/SOQ after RTA at $1200^{\circ} \mathrm{C}$. We found distinct $\mathrm{Si}-\mathrm{Si}$ phonon modes at 512 and $518 \mathrm{~cm}^{-1}$ in the Raman spectra of p-type and n-type films, respectively. The $\mathrm{Si}-{ }^{11} \mathrm{~B}$ and $\mathrm{Si}-{ }^{10} \mathrm{~B}$ modes were observed at 614 and $636 \mathrm{~cm}^{-1}$, respectively, indicating that the B atoms were located at the substitutional sites of the Si lattice. These peak positions are $\sim 4 \mathrm{~cm}^{-1}$ lower than those of $\mathrm{Si}-\mathrm{B}$ modes of $\mathrm{Si}$ NCs reported in the literature ${ }^{16)}$. This downshift is related to the tensile stress in the Si NCs in the Ni-Si NC films, which was caused by the difference between the thermal expansion of $\mathrm{Si}$ and $\mathrm{NiSi}_{2}{ }^{6}$. The peak of the $\mathrm{Si}-\mathrm{Si}$ mode in the p-type $\mathrm{Ni}-\mathrm{Si} \mathrm{NC}$ film exhibits broadening and down-shifting to lower wave numbers, which is attributed to the Fano effect of Raman signals ${ }^{16,17)}$. The Fano effect emerges in Raman spectra of highly doped $\mathrm{Si}$, with p-type $\mathrm{Si}$ showing a stronger Fano effect than n-type Si. The strong Fano effect of the p-type Ni-Si NC films indicates that high-density holes were generated after RTA.

We characterized the carrier-transport properties of B- and P-doped Ni-Si NC films on SOI and SOQ substrates with Hall effect measurements. Figure 3 is a plot of the carrier mobility against the carrier density of the films. The carrier mobility and density were $13-25 \mathrm{~cm}^{2} \mathrm{~V}^{-1} \mathrm{~s}^{-1}$ and $2.5-9.0 \times$ $10^{20} \mathrm{~cm}^{-3}$, respectively, for p-type films and $28-47 \mathrm{~cm}^{2} \mathrm{~V}^{-1} \mathrm{~s}^{-1}$

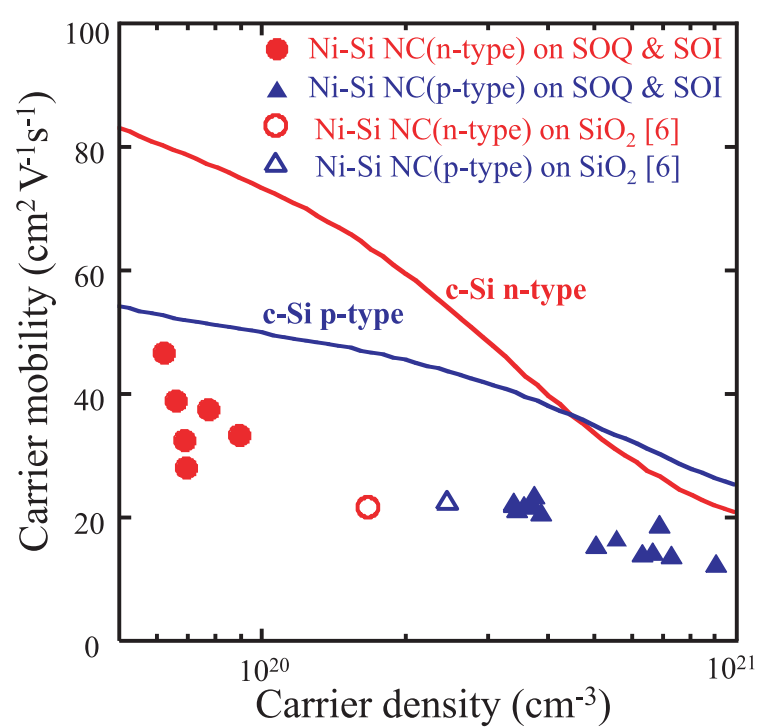

Fig. 3 Carrier mobilities of p-type (filled triangles) and n-type (filled circles) Ni-Si NC films on SOQ and SOI substrates are plotted as functions of carrier density at $30^{\circ} \mathrm{C}$. The solid lines show the carrier mobilities of p-type (blue) and n-type (red) c-Si as functions of the carrier density. ${ }^{18}$ The open circles and triangles show the data of n-type and p-type Ni-Si NC films on $\mathrm{SiO}_{2}$ substrates. ${ }^{6}$ )

and $6.2-8.9 \times 10^{19} \mathrm{~cm}^{-3}$, respectively, for n-type films. Similar to $\mathrm{c}-\mathrm{Si}^{18)}$, the electron and hole mobilities of the $\mathrm{Ni}-\mathrm{Si} \mathrm{NC}$ films were decreased by increasing the carrier density, as shown in Fig. 3.

Apparently, the mobilities of p-type (Ni-Si NC film)/SOQ and p-type (Ni-Si NC film)/SOI are lower than that of the film on $\mathrm{SiO}_{2}$, while n-type (Ni-Si NC film)/SOQ and n-type (N-Si NC film)/SOI had the highest mobilities among all four film types. However, we should consider that the mobility in Si depends on the carrier density; the mobility decreased with increases in carrier density, as shown in Fig. 3. The electron and hole mobilities of Ni-Si NC films on the SOI and SOQ substrates were 52 and $59 \%$, respectively, of the values for the p-type c-Si, while those of (Ni-Si NC film) $/ \mathrm{SiO}_{2}$ were 34 (electron) and $55 \%$ (hole) of the values for $\mathrm{c}-\mathrm{Si}^{6}$ ) . Thus, the mobility was clearly improved for the films that were grown on the SOI and SOQ substrates. The lowest resistivities $(\rho)$ were $1.9 \times 10^{-5} \Omega \mathrm{m}$ for n-type and $5.2 \times 10^{-6} \Omega \mathrm{m}$ for p-type Ni-Si NC films on the SOI and SOQ substrates. These resistivities are lower than those of (Ni-Si NC film)/ $\mathrm{SiO}_{2}$ substrates ${ }^{6)}$.

The $S$ and $\kappa$ values of (Ni-Si NC film)/SOQ were measured using the STPM system. Figure 4(a) and (b) shows the STPM mapping of $S$ and $\kappa$ at $300 \mathrm{~K}$ for the B-doped (Ni-Si $\mathrm{NC}$ film)/SOQ after RTA at $1200^{\circ} \mathrm{C}$. The size of the mapping area was $5.5 \times 5.5 \mathrm{~mm}^{2}$, and the spatial resolution was $250 \mu \mathrm{m}$. The $S$ values varied from 136 to $200 \mu \mathrm{V} \mathrm{K}^{-1}$, as shown in Fig. 4(a). This variation may reflect the fluctuation of the local carrier density of the Ni-Si NC film, resulting from undulations of the annealing-temperature distribution caused by the distribution of the infrared light intensity in the RTA furnace, as previously reported for a Ni-Si NC film on a $\mathrm{SiO}_{2}$ substrate ${ }^{6)}$. As shown in the histogram of the $S$ values in Fig. 4(d), most of the $S$ values were distributed between 140 and $170 \mu \mathrm{V} \mathrm{K}^{-1}$ and the average value was estimated to be 
(a)
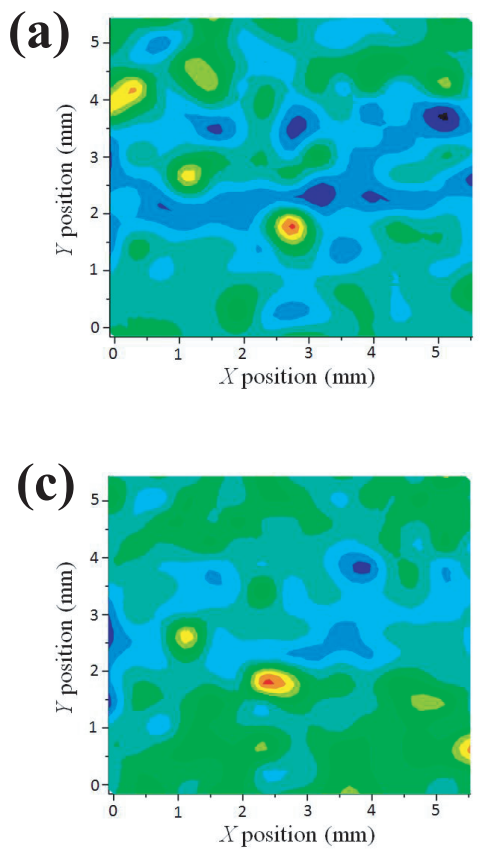
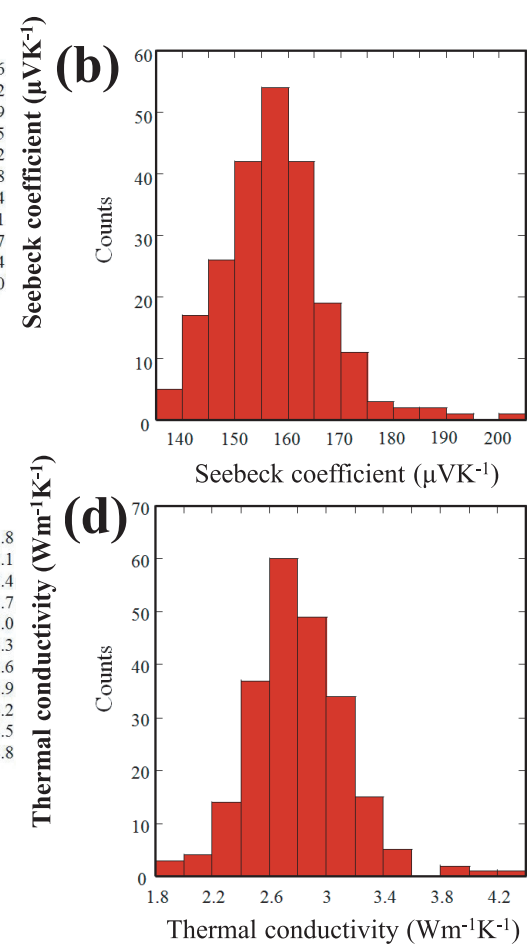

Fig. 4 STPM mapping (mapping area: $5.5 \times 5.5 \mathrm{~mm}^{2}$; spatial resolution: $250 \mu \mathrm{m}$ ) of (a) $S$ and (b) $\kappa$ values at $30^{\circ} \mathrm{C}$ for p-type Ni-Si NC film on SOQ substrate after RTA at $1200^{\circ} \mathrm{C}$. Histograms of (c) $S$ values and (d) $K$ values.

$157 \mu \mathrm{V} \mathrm{K} \mathrm{K}^{-1}$. This fluctuation may have been caused by the variations in carrier density in the $\mathrm{Ni}-\mathrm{Si} \mathrm{NC}$ film because the $S$ value is sensitive to the carrier density.

We measured the heat effusivities $(\varepsilon)$ of the Ni-Si NC films with the STPM system and estimated the value of $\kappa$ using $\kappa=$ $\varepsilon^{2} / c d$, where $c$ is the specific heat capacity and $d$ is the atomic density of the films. In the calculation, we used the following values for the Ni-Si NC film: a specific heat capacity of $0.66 \mathrm{Jg}^{-1} \mathrm{~K}^{-1}$ and atomic density of $2.579 \mathrm{~g} \mathrm{~cm}^{-3}$. The volume ratio between the $\mathrm{Si}$ and $\mathrm{NiSi}_{2}$ regions was estimated to be $\mathrm{Si} / \mathrm{NiSi}_{2}=9: 1$ from the composition of the film $\left(\mathrm{Ni}_{0.95} \mathrm{Si}_{0.05}\right)$ and the atomic densities $\left(2.329 \mathrm{~g} \mathrm{~cm}^{-3}\right.$ for Si and $4.83 \mathrm{~g} \mathrm{~cm}^{-3}$ for $\left.\mathrm{NiSi}_{2}\right)^{19)}$. The specific heat capacity of the Ni-Si NC film was estimated to be $0.66 \mathrm{Jg}^{-1} \mathrm{~K}^{-1}$ from a combination of the specific heat capacity of $0.712 \mathrm{Jg}^{-1} \mathrm{~K}^{-1}$ for $\mathrm{Si}^{20)}$ and $0.1925 \mathrm{Jg}^{-1} \mathrm{~K}^{-1}$ for $\mathrm{NiSi}_{2}{ }^{19)}$ based on the $\mathrm{Si} / \mathrm{NiSi}_{2}$ volume ratio. The $\kappa$ values were mainly distributed in range of $2.2-$ 3.4 $\mathrm{Wm}^{-1} \mathrm{~K}^{-1}$, as shown in Fig. 4(d), which may reflect the local structural variations in the film such as agglomeration of $\mathrm{Si}$ and $\mathrm{NiSi}_{2} \mathrm{NCs}$ and formation of voids, and defects. The average $\kappa$ value $\left(\kappa_{\text {avg }}\right)$ was calculated to be $2.8 \mathrm{Wm}^{-1} \mathrm{~K}^{-1}$.

The average of the absolute values of local Seebeck coefficients $\left(S_{\text {avg }}\right)$, calculated using the STPM mapping data, is plotted as a function of the carrier density for the p-type and n-type (Ni-Si NC film)/SOQ in Fig. 5. The $S_{\text {avg }}$ values were distributed in the range of $113-157 \mu \mathrm{VK}^{-1}$ for p-type films and $170-217 \mu \mathrm{VK}^{-1}$ for $\mathrm{n}$-type films, decreasing with increasing carrier density in both film types, as is the case in single-crystalline $\mathrm{Si}^{21-23)}$. The $S_{\text {avg }}$ value of p-type $\mathrm{Ni}-\mathrm{Si} \mathrm{NC}$ films are larger than that of films on $\mathrm{c}-\mathrm{Si}$ at $\mathrm{RT}^{23)}$, probably because of the energy-filtering effects ${ }^{8)}$ : carriers with energy below the Fermi level of Si NCs were filtered by potential barriers at the grain boundaries of $\mathrm{Si}$ and $\mathrm{NiSi}_{2} \mathrm{NCs}$ in the

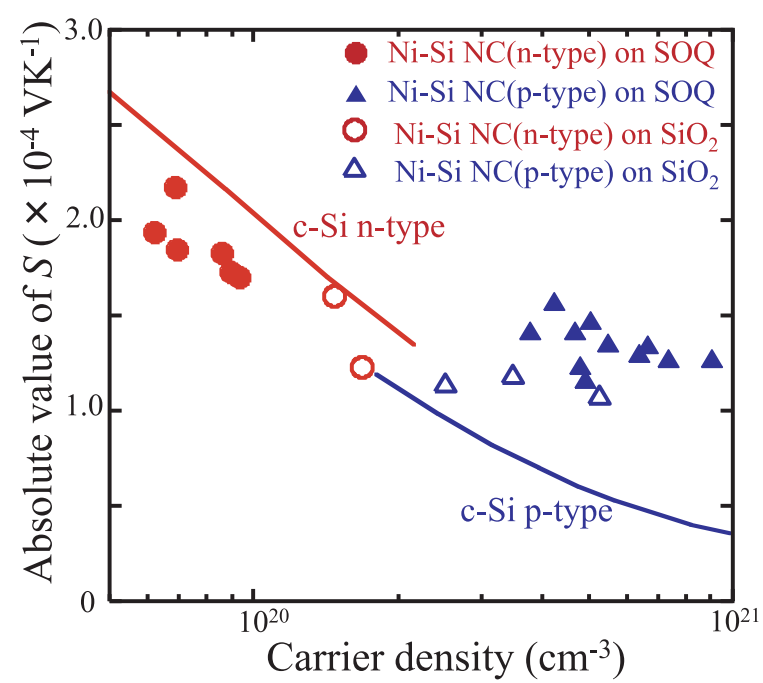

Fig. 5 Absolute values of $S$ for p-type (filled triangles) and n-type (filled circles) Ni-Si NC films on SOQ after RTA at $1200^{\circ} \mathrm{C}$ and $\mathrm{SiO}_{2}$ substrates after RTA at $1200^{\circ} \mathrm{C}$, obtained from STPM mapping, are plotted as functions of carrier density at $30^{\circ} \mathrm{C}$. The solid lines show the absolute values of $S$ for p-type (blue) and n-type (red) c-Si as functions of carrier density. ${ }^{23)}$

films, leading to an increase in the Seebeck coefficient because the low energy carriers had reduced the Seebeck coefficient with the negative portion of the distribution. The carrier density was a key factor of the energy-filtering effect because the Fermi level positions were strongly related to the carrier density in the Si NCs. In the n-type Ni-Si NC films, the electron density of $6.2-8.9 \times 10^{19} \mathrm{~cm}^{-3}$ may not have been enough to obtain the filtering effect.

In Fig. 6, the values of $Z T$ of (Ni-Si NC film)/SOQ and 


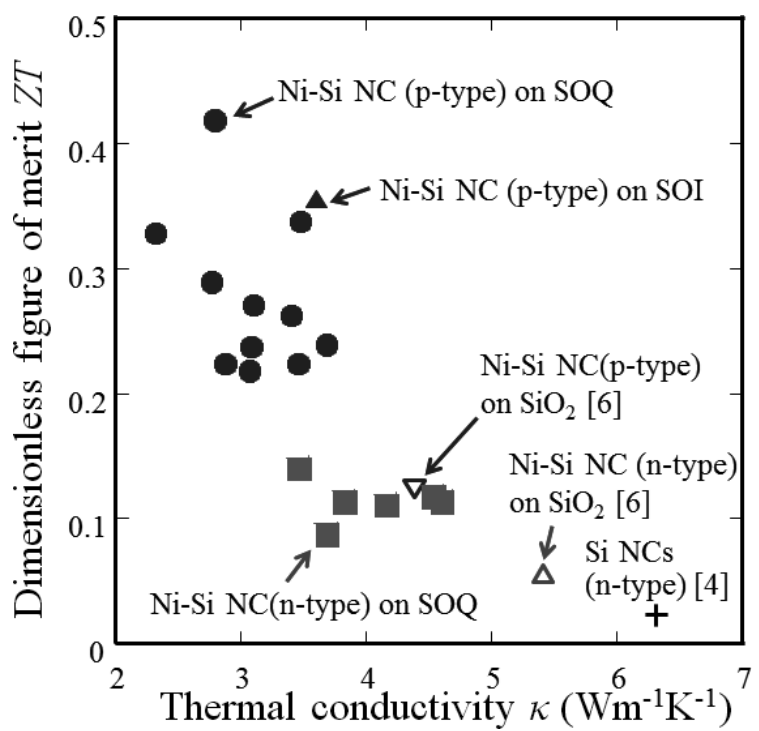

Fig. 6 Plots of $Z T$ as a function of $\kappa$ for p-type and n-type Ni-Si NC films on SOI and SOQ substrates after RTA at $1200^{\circ} \mathrm{C}$, p-type and n-type Ni-Si $\mathrm{NC}$ films on and $\mathrm{SiO}_{2}$ substrates ${ }^{6)}$, and n-type bulk $\mathrm{Si} \mathrm{NCs}{ }^{4)}$ at $30^{\circ} \mathrm{C}$.

(Ni-Si NC film)/SOI at $300 \mathrm{~K}$ are plotted as functions of $\kappa_{\text {avg }}$ measured using the STPM method. The $\kappa_{\text {avg }}$ values were $2.2-$ $3.8 \mathrm{Wm}^{-1} \mathrm{~K}^{-1}$ for the p-type $\mathrm{Ni}-\mathrm{Si} \mathrm{NC}$ films and 3.4 $4.7 \mathrm{Wm}^{-1} \mathrm{~K}^{-1}$ for the n-type Ni-Si NC films. The $\kappa$ value of the p-type (Ni-Si NC film)/SOI was estimated to be $3.6 \mathrm{Wm}^{-1} \mathrm{~K}^{-1}$ using the TCN-2 $\omega$ method ${ }^{6,7,11-13)}$. Nakamura et al. used this method to measure the thermal conductance of $\mathrm{Si}$ NC films which have similar nanostructures with our Ni-Si $\mathrm{NC}$ films ${ }^{12}$. We observed good correspondence between the $\kappa_{\text {avg }}$ and $\kappa$ value obtained from two different measurement methods of the thermal conductivity for orientational grown $\mathrm{Ni}-\mathrm{Si} \mathrm{NC}$ films. As mentioned above, the $\kappa_{\mathrm{avg}}$ and $\kappa$ value reflect the isotropic and vertical heat transport properties, respectively. The correspondence between $\kappa_{\text {avg }}$ and $\kappa$ value suggests that phonon scattering centers to reduce the Si thermal conductivity are distributed uniformly in the Ni-Si films. The $\kappa_{\text {avg }}$ values of p-type and n-type ( $\mathrm{Ni}-\mathrm{Si} \mathrm{NC}$ film) $/ \mathrm{SiO}_{2}$ were estimated to be $3.6-4.4 \mathrm{Wm}^{-1} \mathrm{~K}^{-1}$ and $5.4-5.8 \mathrm{Wm}^{-1} \mathrm{~K}^{-1}$, respectively, after RTA at $1150-1200^{\circ} \mathrm{C}^{6)}$, which were found to be higher than the thermal conductivities of (Ni-Si NC film)/ $\mathrm{SOI}$ and (Ni-Si NC film)/SOQ; this was caused by increases in planar and twin defects in the (Ni-Si NC film)/SOI and (Ni-Si NC film)/SOQ, which could be strong phonon scattering centers. As mentioned earlier, these defects were generated with higher densities in the (Ni-Si NC film)/SOI and ( $\mathrm{Ni}-$ $\mathrm{Si} \mathrm{NC}$ film)/SOQ than in the (Ni-Si NC film)/ $\mathrm{SiO}_{2}$. We found that the $Z T$ values were distributed into $0.2-0.42$ for p-type and 0.08-0.14 for n-type Ni-Si NC film. The fluctuation of $Z T$ values is caused by mainly variation of the Seebeck values which are altered by the carrier densities as shown in Fig. 5. Accurate control of the carrier density in the Ni-Si NC films was difficult because of rough control of initial density of dopant atoms owing to the sputtering deposition and external diffusion from $\mathrm{Si}$ area in the film owing to the high temperature annealing. The range of carrier densities was 3.8$5.0 \times 10^{20} \mathrm{~cm}^{-3}$ to obtain relatively high $Z T$ values of $0.3-0.42$ for p-type Ni-Si NC films at room temperature. The $Z T$ values
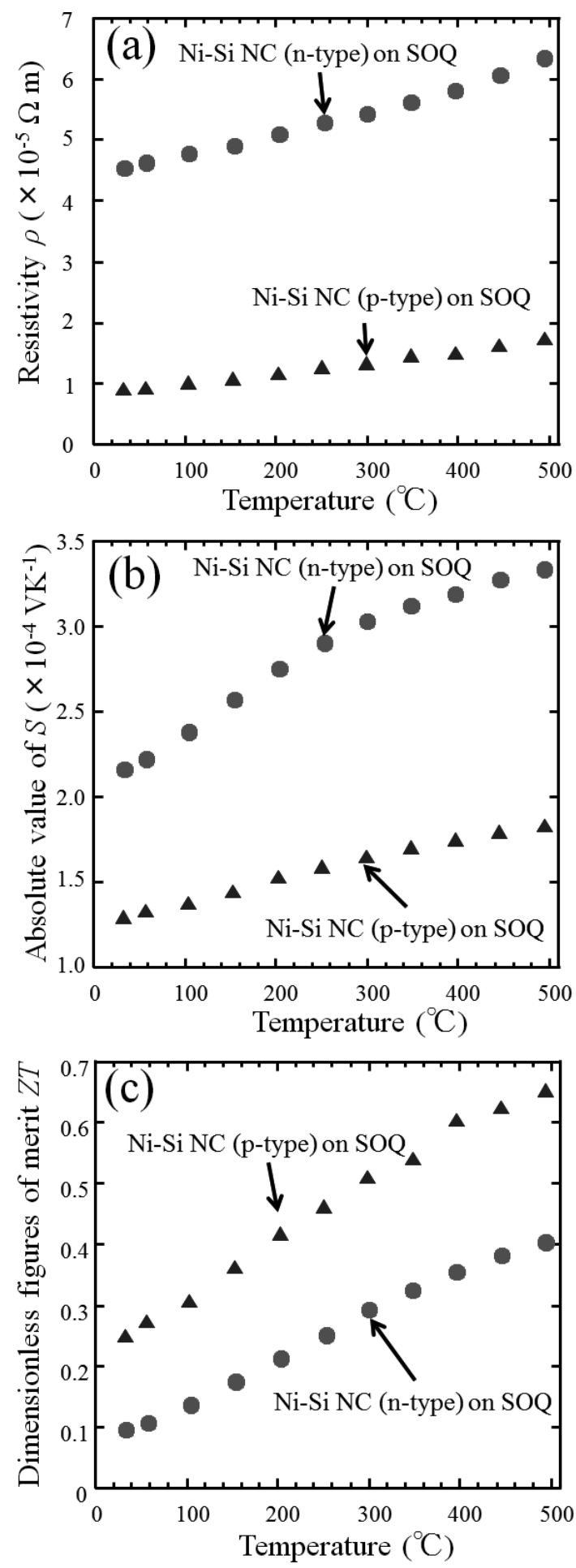

Fig. 7 Temperature dependence of (a) $\rho$, (b) absolute $S$, and (c) $Z T$ values of p-type Ni-Si NC film on SOQ after RTA at $1230^{\circ} \mathrm{C}$ and n-type Ni-Si $\mathrm{NC}$ film on SOQ after RTA at $1200^{\circ} \mathrm{C}$, measured with a ZEM-3 electrical resistance measuring system in the temperature range from 30 to $500^{\circ} \mathrm{C}$.

for the (Ni-Si NC films)/SOI and (Ni-Si NC films)/SOQ were higher than those of the ( $\mathrm{Ni}-\mathrm{Si} \mathrm{NC}$ films) $/ \mathrm{SiO}_{2}$, owing to reduction of thermal conductivity for p-type and n-type, and increase of Seebeck coefficient for p-type films as shown in Fig. 5, and improvement of the electric mobility for n-type films as shown in Fig. 3.

The temperature dependence of the resistivity $\rho$, absolute $S$, and $Z T$ for the p-type and n-type (Ni-Si NC film)/SOQ 
was measured from 30 to $500^{\circ} \mathrm{C}$, as shown in Fig 7. We used the ZEM-3 system to obtain the temperature-dependent $S$ and $\rho$ values of the films. As shown in Fig. 7 (a), the $\rho$ values increased with temperature for both p-type and n-type films. The p-type film had higher electrical conductivity than the n-type film because the former had a higher carrier concentration, as shown in Fig. 5. The absolute $S$ values of the n-type films are higher than those of the p-type film in the temperature range from 30 to $500^{\circ} \mathrm{C}$, as shown in Fig. 7 (b). The $S$ values are consistent with the $S_{\text {avg }}$ values obtained by STPM mapping of the p-type film at $30^{\circ} \mathrm{C}\left(S\right.$ and $\left.S_{\text {avg }}=\sim 130 \mu \mathrm{VK}^{-1}\right)$, while the $S_{\text {avg }}$ values were estimated to be lower than absolute $S$ values for the n-type film $\left(|S|=210 \mu \mathrm{VK}^{-1}\right.$ and $S_{\text {avg }}=$ $\left.170 \mu \mathrm{VK}^{-1}\right)$ at $30^{\circ} \mathrm{C}$. The increase in absolute $S$ values of p-type and n-type films was observed in the temperature range from 30 to $500^{\circ} \mathrm{C}$, as shown in Fig. 7(b). The Seebeck coefficients of the n-type film were much higher than those of the p-type film with increasing temperature, reaching $330 \mu \mathrm{VK}^{-1}$ for the n-type film and $180 \mu \mathrm{VK}^{-1}$ for the p-type film at $500^{\circ} \mathrm{C}$. To calculate $Z T$ of the films, we used constant values of $\kappa, 2.3 \mathrm{Wm}^{-1} \mathrm{~K}^{-1}$ for the p-type film and $3.3 \mathrm{Wm}^{-1} \mathrm{~K}^{-1}$ for the n-type film measured using STPM method at $30^{\circ} \mathrm{C}$, because it was reported that the value of $\kappa$ of highly doped n-type nano-bulk $\mathrm{Si}$ was almost temperature-independent from 30 to $500^{\circ} \mathrm{C}^{4)}$. In Fig. 7(c), ZT increased with temperature for p-type and n-type films and were estimated to be 0.65 and 0.40 at $500^{\circ} \mathrm{C}$, respectively. These $Z T$ values of $(\mathrm{Ni}-\mathrm{Si}$ $\mathrm{NC}$ film)/SOQ are larger than that of n-type nano-bulk $\mathrm{Si}^{4)}$ as well as $\left(\mathrm{Ni}-\mathrm{Si} \mathrm{NC}\right.$ film) $/ \mathrm{SiO}_{2}{ }^{6,24)}$ in the temperature range of $30-500^{\circ} \mathrm{C}$.

\section{Conclusion}

In summary, the thermoelectric properties of $\mathrm{Ni}-\mathrm{Si} \mathrm{NC}$ films were improved by using SOI and SOQ substrates instead of $\mathrm{SiO}_{2}$ substrates. Solid-phase orientational growth of $\mathrm{Si}$ regions in the films was observed in the cross-sectional TEM images. Compared with the Ni-Si NC films on the $\mathrm{SiO}_{2}$ substrates, the carrier mobility was enhanced by the orientational growth. Moreover, the thermal conductivities of the $\mathrm{Ni}-\mathrm{Si}$ NC films on SOI and SOQ substrates were smaller than those of the Ni-Si NC films on the $\mathrm{SiO}_{2}$ substrates, because the density of planar and twin defects increased in the oriented grown films. The $Z T$ values of p-type and n-type orientational Ni-Si films were $0.22-0.42$ and $0.08-0.14$, respectively, at $30^{\circ} \mathrm{C}$. The $Z T$ values of p-type and n-type orientational $\mathrm{Ni}-\mathrm{Si} \mathrm{NC}$ films were increased to 0.65 and 0.40 at $500^{\circ} \mathrm{C}$.

\section{Acknowledgements}

The authors are indebted to Prof. M. Ishimaru of Kyushu Institute of Technology for our valuable discussion on TEM images. A part of this work was supported by the Advanced
Low Carbon Technology Research and Development Program of the Japan Science and Technology Agency (JSTALCA).

\section{REFERENCES}

1) H.R. Shanks, P.D. Maycock, P.H. Sidles and G.C. Danielson: Phys. Rev. 130 (1963) 1743-1748.

2) A.I. Hochbaum, R. Chen, R.D. Delgado, W. Liang, E.C. Garnett, M. Najarian, A. Majumdar and P. Yang: Nature 451 (2008) 163-167.

3) A.I. Boukai, Y. Bunimovich, J. Tahir-Kheli, J.K. Yu, W.A. Goddard and J.R. Heath: Nature 451 (2008) 168-171.

4) S.K. Bux, R.G. Blair, P.K. Gogna, H. Lee, G. Chen, M.S. Dresselhaus, R.B. Kaner and J.-P. Fleurial: Adv. Funct. Mater. 19 (2009) 2445-2452.

5) Z. Wang, J.E. Alaniz, W. Jang, J.E. Garay and C. Dames: Nano Lett. 11 (2011) 2206-2213.

6) N. Uchida, T. Tada, Y. Ohishi, Y. Miyazaki, K. Kurosaki and S. Yamanaka: J. Appl. Phys. 114 (2013) 134311-1-6.

7) Y. Ohishi, K. Kurosaki, T. Suzuki, H. Muta, S. Yamanaka, N. Uchida, T. Tada and T. Kanayama: Thin Solid Films 534 (2013) 238-241.

8) A.J. Mannich, M.S. Dresselhaus, Z.F. Ren and G. Chen: Energy Environ. Sci. 2 (2009) 466-479.

9) A. Yamamoto, D. Kukuruznyak, P. Ahmet, T. Chikyow and F. S. Ohuchi: Combinatorial and Artificial Intelligence Methods in Materials Science II: Materials Research Society Symposium Proceedings, Vol. 804, Boston, Massachusetts, USA, 1-3 December 2003, edited by T. Chikyow, A. Karim, R.A. Potyrailo and Q. Wang (Cambridge University Press, New York, 2004) pp. 3-14 (JJ1.4).

10) A. Yamamoto, T. Noguchi, H. Obara, K. Ueno, S. Ikeuchi, T. Sugawara, K. Shimada, Y. Takasaki and Y. Ishii: Combinatorial Methods for High-Throughput Materials Science: Materials Research Society Proceedings, Vol. 1024, Boston, Massachusetts, USA,26-30 November 2007, edited by D. S. Ginley, M. J. Fasolka, A. Ludwig and M. Lippmaa (Cambridge University Press, New York, 2008) pp. 24-29 (A01-05).

11) R. Kato and I. Hatta: Int. J. Thermophys. 26 (2005) 179-190.

12) Y. Nakamura, M. Isogawa, T. Ueda, S. Yamasaka, H. Matsui, J. Kikkawa, S. Ikeuchi, T. Oyake, T. Hori, J. Shiomi and A. Sakai: Nano Energy 12 (2015) 845-851.

13) N. Uchida, Y. Ohishi, K. Kurosaki, S. Yamanaka, T. Tada, and T. Kanayama, in MRS Proceedings (2013), Vol. 1456 DOI:10.1557/ opl.2013.533.

14) C. Kim, K. Kurosaki, M. Ishimaru, H. Muta and S. Yamanaka: J. Electron. Mater. 40 (2011) 999-1004.

15) K. Biswas, J. He1, I.D. Blum, C-I. Wu, T.P. Hogan, D.N. Seidman, V.P Dravid, and M.G. Kanatzidis: Nature 489 (2012), 414-418.

16) K. Sato, K. Niino, N. Fukata, K. Hirakuri and Y. Yamauchi: Nanotechnology 20 (2009) 365207-1-6.

17) U. Fano: Phys. Rev. 124 (1961) 1866-1878.

18) G. Masetti, M. Severi and S. Solmi: IEEE Trans. Electron Devices 30 (1983) 764.

19) D. L. Perry, Handbook of Inorganic Compounds, $2^{\text {nd }}$ edition (CRC Press, Boca Raton, Florida, 2010) pp. 290, 361.

20) J. Acker and K. Bohmhmmel: Thermochim. Acta 337 (1999) 187-193.

21) T.H. Geballe and G.W. Hull: Phys. Rev. 98 (1955) 940-947.

22) A. Stranz, J. Kahler, A. Waag and E. Peiner: J. Electron. Mater. 42 (2013) 2381-2387.

23) Y. Ohishi, J. Xie, Y. Miyazaki, Y. Aikebaier, H. Muta, K. Kurosaki, S. Yamanaka, N. Uchida and T. Tada: Jpn. J. Appl. Phys. 54 (2015) 071301-1-6.

24) Y. Ohishi, Y. Miyazaki, H. Muta, K. Kurosaki, S. Yamanaka, N. Uchida and T. Tada: J. Electron. Mater. 44 (2015) 2074-2079. 